\title{
Validation of the French version of Object Spatial Imagery and Verbal Questionnaire.
}

\author{
C. BLED* \\ L. BOUVET* \\ *Université Toulouse Jean Jaurès, Laboratoire CERPPS-E.A. 7411, Toulouse, France.
}

\section{Corresponding Author:}

Clara Bled,

Ph.D Candidate

\section{CERPPS (EA 7411)}

5, allée Antonio Machado

31058 Toulouse, FRANCE

E-mail: clara.bled@univ-tlse2.fr

Tel : +33 (0)646 840569 


\begin{abstract}
The Object Spatial Imagery and Verbal Questionnaire (OSIVQ) measures individual differences in Visual-Verbal cognitive style and distinguishes between spatial and object visual imagery. This article aims to validate the francophone version of the OSIVQ using sensitive measures of spatial imagery, object imagery and verbal abilities among a French sample $(\mathrm{N}=752)$. Principal component analyses of the OSIVQ showed good internal construct although 11 items had to be removed. Individual differences were found with participants that tended to rate themselves higher on the object scale. Results also revealed a significant gender effect. Indeed, males had higher spatial scores while females had higher object scores. Confirmatory factorial analyses gave support to three-dimensional model of cognitive style. Furthermore, correlations were observed across the different dimensions of the questionnaire and specific paper-and-pencil tasks. In the end, this study highlights the good psychometric properties of the French version of the OSIVQ.
\end{abstract}

Keywords: cognitive style, object imagery, spatial imagery, psychometric proprieties, questionnaire, French validation 
Cognitive styles refer to psychological dimensions representing consistencies in an individual's manner of cognitive functioning, particularly with respect to acquiring and processing information (Messik, 1976). Many forms of cognitive styles have been described but the most frequently used is the visual-verbal style (Kozhevnikov, 2007). The visual-verbal style is based on the dual-coding theory according to which information is processed and mentally represented in two ways: verbally and visually (Paivio, 1991). Visual-Verbal cognitive style therefore describes consistencies and preferences in processing visual versus verbal information. Mayer \& Massa (2003), further define the "visualizer-verbalizer cognitive style" as thinking in pictures or words. These preferences reflect "heuristics and individual uses to process information about his or her environment" (Kozhevnikov, 2007).

Visual representation (or visual mental imagery) has long been considered to be of a unitary nature, but Koshevnikov and her team have provided evidence for two distinct types of visual mental imagery: object and spatial imagery (Kozhevnikov et al., 2002; Kozhevnikov, Motes, and Hegarty, 2007). Object imagery allows pictorial and analogous representations of objects and scenes, whereas spatial imagery is more a schematic representation of objects and patterns with their spatial relationships. This conception is supported by brain research showing the existence of two distinct neuronal pathways for the processing of different aspects of visual information (Farah et al., 1988; Kosslyn, 2005; Kosslyn et al., 2006). The ventral pathway is dedicated to processing the visual appearance of objects and scenes in terms of their shape, color and texture. The dorsal pathway processes object location, movement, spatial relationships and transformations (Kosslyn et al., 2001; Mazard et al., 2004). Furthermore, visuo-spatial abilities are associated with a more efficient use of the dorsal pathway (Mayer \& Massa, 2003; Lamm, Bauer, Vitouch, \& Gstattner, 1999) whereas visuo-object abilities are associated with a more efficient use of the ventral pathway (Motes, Malach \& Kozhevnikov, 2008). In this context, object versus spatial cognitive styles refer to 
an individual's preferences or habits of processing information in terms of object and spatial visual mental imagery.

Numerous self-reported questionnaires were created to assess cognitive style, the most famous one being the Verbalizer-Visualizer Questionnaire (VVQ; Richardson, 1977). However, the VVQ has been criticized for poor internal reliability (Boswell and Pickett, 1991). Moreover, the visual subscale of this questionnaire did not correlate with visual-spatial aptitude measures, which suggests a lack of predictive validity of the VVQ (Mayer \& Massa, 2003). This lack of predictive validity is also observed in other cognitive style questionnaires as noted in Kozhevnikov's review on cognitive style (Kozhevnikov, 2007). As pre-existing questionnaires presented certain flaws and none of them evaluated the two dimensions of visual mental imagery, Blajenkova and Kozhevnikov developed the Object Spatial Imagery and Verbal Questionnaire (OSIVQ; Blazhenkova \& Kozhevnikov, 2009). The OSIVQ thus evaluates three dimensions of cognitive style: object imagery, spatial imagery and verbal.

Blajenkova and Kozhevnikov evaluated the psychometric properties of the OSIVQ on 625 students. They found that the OSIVQ showed good internal construct (with a three-factor solution of a principal component analysis), good internal consistency (for the verbal scale, Cronbach alpha reached .74 ; for the object scale, $\alpha=.83$ and for the spatial scale, $\alpha=.79$ ) (Blazhenkova \& Kozhevnikov, 2009). Furthermore, the OSIVQ demonstrated acceptable testretest reliability with significant correlations between testing sessions $(r=.73$ for the verbal scale, $r=.75$ for the object scale and $r=.84$ for the spatial scale).

Moreover, unlike many previous questionnaires, OSIVQ scores significantly correlated with performances on different tasks assuring convergent validity of the instrument. "Object visualizers" were found to have good performances in object imagery tasks that require vivid visualization of pictorial properties (e.g., recognizing degraded objects) whereas "spatial 
visualizers" had good performances during spatial imagery tasks that involve visualization of schematic representations and spatial transformations (e.g., mental rotation) (Blajenkova et al., 2006; Kozhevnikov et al., 2005). Finally, OSIVQ scores predicted professional interests or courses choices. Visual artists were generally "object visualizers" and had high object imagery ability, while scientists and engineers were generally "spatial visualizers" and had high spatial imagery ability (Blajenkova et al., 2006; Blazhenkova \& Kozhevnikov, 2009); Blazhenkova \& Kozhevnikov, 2010; Kozhevnikov, Blazhenkova, \& Becker, 2010). The OSIVQ is therefore an ecologically valid scale with good predictive validity and psychometric proprieties.

Our objective is to create a French version of the Object Spatial Imagery and Verbal Questionnaire (OSIVQ) and to explore its psychometric properties with a large sample of the population. The aim is to provide a robust tool to assess cognitive style in the French community while making the distinction between spatial and object imagery.

\section{Material and method}

\section{Participants}

For the exploratory study, 450 participants (121 males and 329 females; age range 18 to 50, Mean $=31.51, \mathrm{SD}=8.90)$ completed the questionnaire. According to the formula $\mathrm{N}=\mathrm{Z}^{*} 10$ (with $\mathrm{N}=$ number of subjects and $\mathrm{Z}=$ number of items) a minimum of 450 subjects is necessary for accurate validation of a questionnaire with 45 items (Hair et al., 1998).

For the confirmatory study, 302 new participants (63 males and 239 females; age range 18 to 50$, Mean $=27.84, \mathrm{SD}=8.85)$ were recruited. 144 of them also took a paper-and-pencil assessment to evaluate spatial imagery, object imagery and verbal abilities in addition to the questionnaire. This number of participants is slightly below the number required according to 
the formula $(\mathrm{N}=34 * 10=340)$.

Participants were recruited by posting an advertisement on social media.

\section{General procedure}

The original English version of the Object Spatial Imagery and Verbal Questionnaire (OSIVQ; Blazhenkova \& Kozhevnikov, 2009) was translated to French using a classical translation-back translation procedure: the original version of the questionnaire was first translated from English into French by a native English-speaking person who is fluent in French. This French version was then translated back into English by a native Frenchspeaking English teacher. The two English versions were then compared in order to validate the French translation. The translated version of the questionnaire is presented in supplementary data.

For the exploratory study, participants responded to our French version of the Object Spatial Imagery and Verbal Questionnaire (OSIVQ) online. The online questionnaire was created using LimeSurvey@, and securely hosted by the University of Toulouse.

For the confirmatory study, participants were administered the French version of the OSIVQ and the following paper-and-pencil assessments: one spatial imagery test (Mental Rotation Test; Vandenberg \& Kuse, 1978), one object imagery assessment (Vividness of Visual Imagery Questionnaire; Marks, 1973) and one verbal test (Mill Hill vocabulary test; Raven, J., Raven, J.C., \& Court, J.H., 2003) described below. The order of tests was randomized.

All participants read an information notice with explanations concerning the study and indicated their consent before beginning. 
This study was approved by the Research Ethics Committee of Toulouse University and received authorization by the French National Commission for Informatics and Freedoms (CNIL) regarding the protection and anonymization of personal data.

\section{Measures}

Object Spatial Imagery and Verbal Questionnaire (OSIVQ; Blazhenkova \& Kozhevnikov, 2009) French translation: OSIVQ is a 45-item self-report questionnaire designed to assess separately an individual's propensities for three different cognitive style dimensions (object imagery, spatial processing and verbal processing). The following instructions were provided to the participants: "This is a questionnaire about the way you think. Please, read the following statements and rate each of them on a 5-point scale. Select 5 to indicate that you absolutely agree that the statement describes you, and select 1 to indicate that you totally disagree with the statement. Select 3 if you are not sure, but try to make a choice. It is very important that you answer all the items in the questionnaire". There was no time limit for the completion of the questionnaire and participants could go back to correct their answers if they wanted.

Mental Rotation Test (MRT; Vandenberg \& Kuse, 1978 French adaptation by J.M. Albaret et E. Aubert, 1990): MRT measures mental rotation ability. Participants compared twodimensional line drawings of three-dimensional geometric figures composed of cubes. Each test-item consisted of a target figure and four comparison figures. Two of the comparison figures were rotated versions of the target figure, and the other two comparison figures were rotated mirror images of the target figure. Participants were to indicate which two of the four figures were the rotated versions of the target figure. There are two parts with 10 items each and participants have 3 minutes to complete each part of the test. 2 points were awarded for 
each item with 2 correct answers, 1 point if only one of the drawings was chosen and it was correct, 0 points if at least one of the two choices was incorrect.

Vividness of Visual Imagery Questionnaire (VVIQ; Marks, 1973 French translation by Santarpia et Poinsot, 2007): The VVIQ is a frequently used self-report measure of the vividness of visual mental images. Participants had to rate the vividness of mental images they were asked to create (e.g. "The sun is rising above the horizon into a hazy sky and a strong wind blows on the trees and on the lake, causing waves"). Participants responded on a 5-point scale (from "no picture at all" to "a perfectly clear and vivid picture"). There are 16 items and each item is scored from 1 to 5 and the total score (sum of the scores of all items) gives an indication of the importance of the vividness of mental images.

Mill Hill vocabulary test (Raven, J., Raven, J.C., \& Court, J.H., 2003 French adaptation by J.J. Deltour, 1993): This test assesses vocabulary knowledge and verbal skills. In this paper and pencil test, participants had to choose and circle the word that has either the same meaning or nearly the same meaning (synonym) as the target word, among six others in a printed list. There are 34 items.

\section{Data analysis}

One spatial and three verbal items were negatively formulated and therefore reversed for the analysis. Exploratory analyses were realized using principal component factor analysis with Varimax rotation using SPSS V23.0 (IBM Corp, 2015). The internal consistency was measured with Cronbach alphas for each subscale of the OSIVQ. McKelvie's (1994) recommended alpha coefficients of .85 in order to accept validity of scales and the minimum acceptable coefficient should not be less than .70 (Nunnally, 1978). For descriptive statistics and 
in order to evaluate a possible gender effect, Student's t-test and repeated measures ANOVA were performed.

In order to assess the psychometric properties of the OSIVQ and its factorial validity, confirmatory factor analysis (CFA) and path analysis were used and computed using AMOS (IBM Corp, 2015). We compared the two models: a two-factor model, as in the traditional model, and a three-factor model, as in Blazhenkova \& Kozhevnikov's model, with a second order CFA analysis. We compared the different models by using fit indices: chi-square test $\left(\chi^{2} / \mathrm{df}\right)$, root mean square error of approximation (RMSEA), Bentler's comparative fit index (CFI), goodness of fit index (GFI) and Akaike information criterion (AIC). It was assumed that the model can be considered satisfactory when the $\chi^{2} / \mathrm{df}$ is lower than 3 , RMSEA and CFI lower than .08 and GFI higher than .90 (Tabachnick and Fidell, 2001). The AIC is a comparative measure of fit and so it is meaningful when two different models are estimated: the lower the value is, the better the fit (Tabachnick and Fidell, 2007).

Convergent validity of the OSIVQ was measured with correlations between the OSIVQ subscales' scores and paper-and-pencil assessment's scores. A correlation with $.30<r<.50$ is considered as low, moderate with $.50<r<.70$ and strong with $r>.70$ (Tabachnick and Fidell, 2001).

\section{Results}

\section{Exploratory study}

\subsection{Principal component analysis}

The initial principal component analysis revealed 11 factors with eigenvalues above 1 . Only three factors, however, had eigenvalues markedly higher $(6.23,5.73$ and 3.29) than the others 
(ranging from 2.05 to 1.02 ), and these first three factors explained a total of $33.88 \%$ of the variance $(13.84 \%, 12.73 \%$ and $7.31 \%)$. None of the other factors met the recommendations for component saturation (Guadagnoli \& Velicer, 1988) and the analysis of the decreasing eigenvalue curve ("scree plot") also revealed a three-factor solution. Therefore, other solutions were not considered further.

Based on these results, a second principal component analysis with Varimax rotation was performed with 3 factors. First of all, the test's conditions of use were checked using the Bartlett test. The sphericity test was significant $\left(\chi^{2}(990)=7321.69, \mathrm{p}<.001\right)$, and the KaiserMeyer-Olkin test $(\mathrm{KMO})$ was greater than $0.80(\mathrm{KMO}=0.839)$, indicating sufficient correlations for component analysis. Items that loaded significantly on multiple factors were removed from the analysis, as were items that did not load significantly (below the critical value of .35) and therefore did not correlate with any factor (Hair et al., 1998). Thus, 11 items $(3,10,15,19,21,22,24,25,28,36$ and 38$)$ were removed from the original questionnaire in order to obtain a coherent structure. The 34 remaining items of the OSIVQ (14 items for the object scale, 11 items for the spatial scale and 9 items for the verbal scale) and their loadings on the 3 factors are presented in Table 1. 
Table 1. Principal component loadings, after Varimax rotation, for the translated OSIVQ items.

\begin{tabular}{llccc}
\hline OSIVQ items & Factor 1 & Factor 2 & Factor 3 \\
Object & Spatial & Verbal \\
\hline 20 & My images are very vivid and photographic & .75 &
\end{tabular}

29 I can easily remember a great deal of visual details that someone else might never notice. For example, I would just automatically take some things in, like what color is a shirt someone wears or what color are his/her shoes

40 I remember everything visually. I can recount what people wore to a dinner and I can talk about the way they sat and the way they looked probably in more detail than I could discuss what they said

34 I can close my eyes and easily picture a scene that I have experienced

33 Sometimes my images are so vivid and persistent that it is difficult to ignore them

$6 \quad$ My images are very colorful and bright

13 I have a photographic memory

43 My visual images are in my head all the time. They are just right there

26 When I imagine the face of a friend, I have a perfectly clear and bright image

11 When reading fiction, I usually form a clear and detailed mental picture of a scene or room that has been described

45 When I hear a radio announcer or a DJ I've never actually seen, I usually find myself picturing what he or she might look like

23 My mental images of different objects very much resemble the size, shape and color of actual objects that I have seen

18 When entering a familiar store to get a specific item, I can easily picture the exact location of the target item, the shelf it stands on, how it is arranged and the surrounding articles

12 If I were asked to choose among engineering professions, or visual arts, I would choose visual arts

1 I was very good in 3D geometry as a student

14 I can easily imagine and mentally rotate three-dimensional geometric figures

31 In school, I had no problems with geometry

32 I am good in playing spatial games involving constructing from blocks and paper (e.g. Lego, Tetris, Origami)

44 My graphic abilities would make a career in architecture relatively easy for me

27 I have excellent abilities in technical graphics

42 I find it difficult to imagine how a three-dimensional geometric figure would exactly look like when rotated

30 I can easily sketch a blueprint for a building I am familiar with 9 69 2 (1) a ( 3

7 I prefer schematic diagrams and sketches when reading a textbook instead of colorful and pictorial illustrations

17 When thinking about an abstract concept (or building), I imagine an abstract schematic building in my mind or its blueprint rather than a specific concrete building

5 Architecture interests me more than painting

35 I have better than average fluency in using words

$4 \quad$ My verbal abilities would make a career in language arts relatively easy for me

39 I enjoy being able to rephrase my thoughts in many ways for variety's sake in both writing and speaking

$\begin{array}{lll}41 & \text { I sometimes have a problem expressing exactly what I want to say } & .48 \\ 8 & \text { I tell jokes and stories better than most people } & .38\end{array}$ 
The first factor was identified as object imagery factor, since all of the items designed to assess object imagery experiences positively loading on this factor, whereas all of the items designed to assess spatial imagery or verbal preferences either did not load. The second factor was identified as spatial imagery factor, since all of the items designed to assess spatial imagery preferences loaded positively on the second factor, whereas all of other items did not load on this factor. Finally, the third factor was identified as verbal factor, since all of the items designed to assess verbal preferences loaded positively on the third factor and other items did not load on this factor.

\subsection{Internal consistency}

The internal consistency was measured with Cronbach alphas. For the verbal scale, $\alpha=.76$; for the object scale, $\alpha=.84$ and for the spatial scale, $\alpha=.85$. Cronbach alphas showed a good internal consistency for the three sub-scales, with the selected items.

\subsection{Descriptive statistics and gender differences}

As the result of the selection of the 34 items, the number of items per subscale is not equivalent. Thus, for each participant, the scores for each subscale were transformed into percentages.

For the three subscales, Spatial score's mean is 60.65 ( \pm 17.09$)$; Object score's mean is 72.10 $( \pm 14.39)$ and Verbal score's mean is $66.64( \pm 15.48)$.

We then examined the effect of gender on object-spatial-verbal preferences for information processing, using repeated measures ANOVA, with gender as a between-subject variable, and three OSIVQ scales as within-subject variables. The repeated measures ANOVA demonstrated a significant difference between the three scales of the OSIVQ, F $(2,896)=$ 21.375, $p<.001, \eta^{2}=.046$. Participants tended to rate themselves higher on Object imagery than on Spatial imagery $(p<.001)$ or Verbal dimensions $(p<.001)$ but there was no 
difference between Spatial imagery scores and Verbal scores $(p=.092)$.

The repeated measures ANOVA also showed a trend effect of gender, $\mathrm{F}(1,448)=3.396, p=$ $.066, \eta^{2}=.008$ and a significant Gender*OSIVQ interaction, $\mathrm{F}(2,896)=34.968, p<.001, \eta^{2}$ $=.072$. Males were higher than females on OSIVQ spatial scores $[$ Mean males $=69.80, \mathrm{SD}=$ 1380, Mean females $=57.29, \mathrm{SD}=16.96, \mathrm{t}(448)=7.27, p<.001]$. Females had higher OSIVQ object imagery scores than males [Mean females $=73.56, \mathrm{SD}=14.22$, Mean males $=$ $68.16, \mathrm{SD}=14.15, \mathrm{t}(448)=-3.58, p<.001]$. We found no significant gender difference on OSIVQ verbal scores, $\mathrm{t}(448)=-1.06, p=.288$.

\section{Confirmatory study}

\subsection{Confirmatory factor analysis}

According to the traditional model of Visual-Verbal style, Verbal and Visual styles constitute two opposite dimensions whereas Blazhenkova and Kozhevnikov's theoretical approach distinguishes two types of imagery (object and spatial). Indeed, according to Blazhenkova and Kozhevnikov's revised model of cognitive style, there should be three separate dimensions (object, spatial and verbal). Figure 1 shows the results of the estimated threefactor model, and the values of fit for the different models are reported in Table 2. 


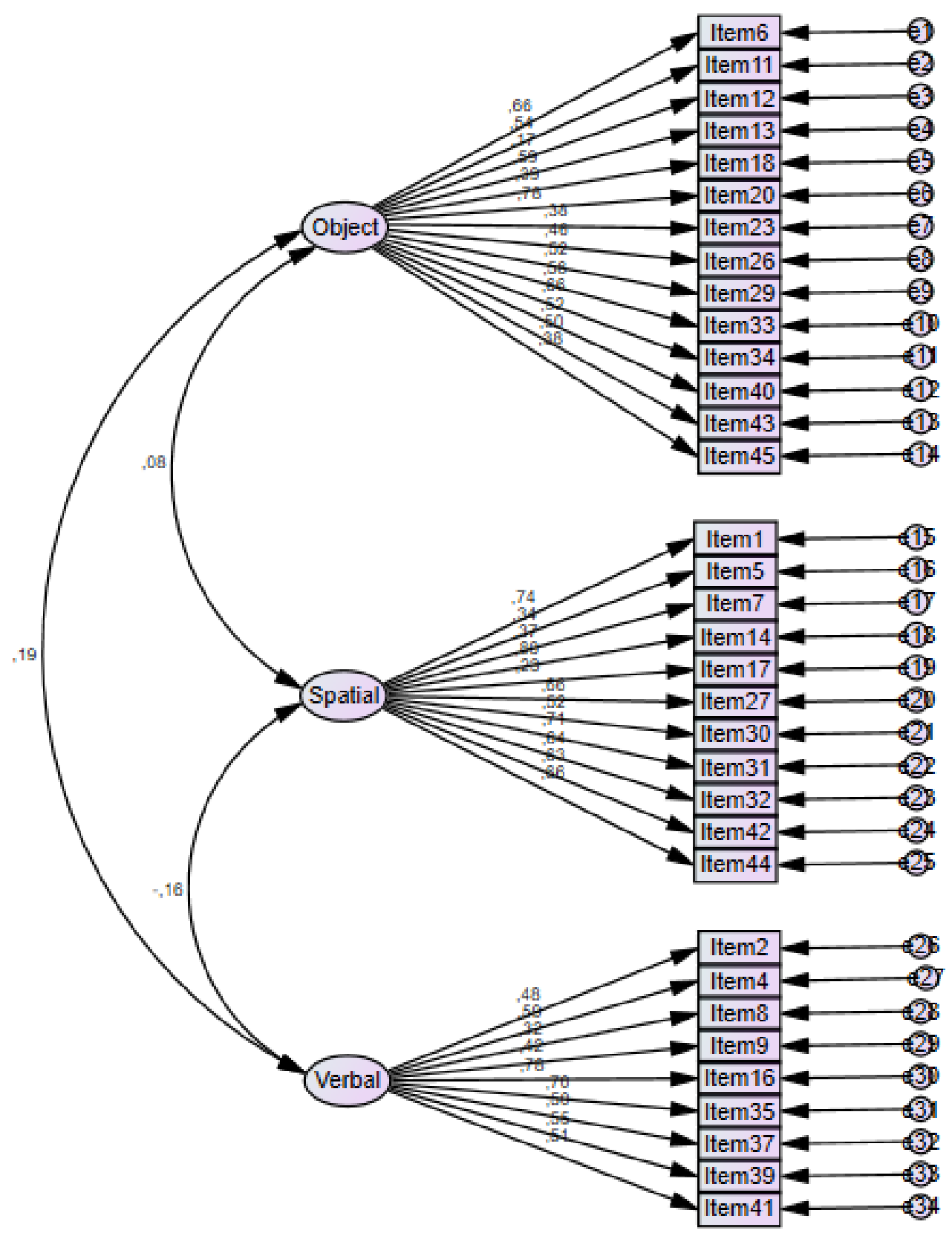

Figure 1. Estimated three-factor model. Numbers above the arrows indicate the standardized factor loadings.

Table 2. Values of fit for the different models

\begin{tabular}{lcccccccc}
\hline Model & $X^{2}$ & $\mathrm{df}$ & $p$-value & $X^{2} / \mathrm{df}$ & $\mathrm{CFI}$ & $\mathrm{GFI}$ & RMSEA & AIC \\
\hline Three-factor with 45 items & 2459.8 & 942 & .001 & 2.61 & .62 & .72 & .07 & 2645.8 \\
Three-factor with 34 items & 1156.1 & 524 & .001 & 2.21 & .79 & .82 & .06 & 1298.1 \\
Two-factor with 34 items & 2087.3 & 526 & .001 & 3.97 & .48 & .61 & .09 & 2225.3 \\
\hline
\end{tabular}

As seen in Figure 1, items from the verbal scale's scores loaded on a "verbal" factor, items from the spatial imagery scale's scores loaded on a "spatial" factor and items from the 
object imagery scale's scores loaded on an "object" factor. Interestingly, results of the confirmatory factor analysis indicated no significant correlation between our three factors $(r=$ -.16 between spatial and verbal factors; $r=.08$ between spatial and object factors and $r=.19$ between object and verbal factors) (see Figure 1).

In order to confirm our item selection, we tested the fit of the three-factor model with all 45 originals items of our translation. According to the values, the fit of our 34 selected items scale is better than the one with the 45 original items (see Table 2).

Secondly, we compared the three-factor and the two-factor models using our 34 selected items. The two-factor model showed poor fit indices and the AIC score was lower than with the three-factor model. Overall, indices suggested that the three-factor model fits the data well which indicates that this model does explain the data. This is why the three-factor solution was retained.

\subsection{Convergent validity}

Correlations among the measures of verbal, spatial and object ability are presented in Table 3 .

Table 3. Matrix of correlations among the OSIVQ spatial, object and verbal scores and paperand-pencil measures

\begin{tabular}{|c|c|c|c|c|c|c|}
\hline Measure & 1 & 2 & 3 & 4 & 5 & 6 \\
\hline 1. Spatial score & - & .04 & $-.17^{* *}$ & -.01 & $.54 * *$ & .04 \\
\hline 2. Object score & & - & $.15^{* *}$ & $.50 * *$ & -.05 & $-.17 *$ \\
\hline 3. Verbal score & & & - & .02 & $-.29 * *$ & $.32 * *$ \\
\hline 4. VVIQ & & & & - & -.05 & -.05 \\
\hline 5. MRT & & & & & - & -.01 \\
\hline 6. Mill Hill & & & & & & \\
\hline
\end{tabular}

OSIVQ verbal scores were positively correlated with the verbal measure (Mill Hill scores) ( $p$ $<.001)$. OSIVQ spatial scores were positively correlated with the measure of spatial imagery (MRT scores) $(p<.001)$. Finally, OSIVQ object imagery scores were positively correlated with the measure of object imagery (VVIQ scores) $(p<.001)$. Thus, all three scales of the OSIVQ 
demonstrated acceptable convergent validity.

Regarding the discriminant validity of the three scales, although none of the OSIVQ scales correlated positively with any task corresponding to the other scales, there is a significant but weak negative correlation between the OSIVQ verbal scores and MRT scores $(r=-.29, p=$ $.001)$.

\section{Discussion}

We developed a French version of the Object Spatial Imagery and Verbal Questionnaire (OSIVQ), a self-report instrument that allows the evaluation of the visual-verbal cognitive style in three dimensions with two imagery (object and spatial) scales and one verbal scale. The first important outcome of the exploratory study is that our translated version of the OSIVQ (with the 34 selected items) demonstrated acceptable internal consistency for all three scales. Furthermore, our principal component analysis also revealed three distinct factors (object, spatial and verbal). These results are thus consistent with Blazhenkova \& Kozhevnikov's model of cognitive style (Blazhenkova \& Kozhevnikov, 2009).

Another important finding is that the distribution of object, spatial and verbal scores differs among the three subscales. Indeed, participants tend to rate themselves higher on the object imagery scale than on other scales. This trend is consistent with previous findings (Blazhenkova \& Kozhevnikov, 2009; Chabris et al., 2006). In addition, we also reported a significant gender effect with females tending to report themselves as object visualizers and males as spatial visualizers. This difference is not surprising as preceding studies reported a gender difference on spatial tasks with males performing better than females (Linn \& Petersen, 1985) and higher spatial imagery ratings for males while females tend to report higher object imagery and imagery vividness (Blajenkova et al., 2006). According to Blajenkova et al., 
difference between spatial and object visualizers, however, cannot be reduced to gender differences (Blajenkova et al., 2006; Kozhevnikov et al., 2005). Actually, $40.42 \%$ of our female participants reported above average spatial imagery preferences and $38.02 \%$ of male participants reported above average object imagery preferences. Furthermore, using partial correlations, Blajenkova and Kozhevnikov found that all the significant correlations between different object, spatial and verbal scales and corresponding objective measures remained significant even after the effect of gender was partialled out (Blazhenkova \& Kozhevnikov, 2009).

Regarding the confirmatory study, it provides further validation of our French version of the OSIVQ. The traditional two-factor model that describes Visual-Verbal cognitive style as a bipolar dimension was compared to the three-factor model that comprises three independent dimensions (verbal, object and spatial). The results of our confirmatory factor analysis indicate that the overall fit of the three-factor model was indeed significantly greater than that of the two-factor model. It should be noted that our number of participants for the confirmatory study is a little below the recommended minimal number needed which might explain why the fit of our three-factor model is satisfactory but could be improved if a larger sample was tested. Overall, these findings provide again support for the Blazhenkova \& Kozhevnikov's three-dimensional model of cognitive style.

At last, our translation demonstrated acceptable convergent validity. Indeed, participants' ratings on the object, spatial and verbal scales correlate positively with the corresponding task only. Although we did not find significant correlations between the verbal and spatial factors nor between OSIVQ verbal and spatial scores, we did find a weak but significant negative correlation between the OSIVQ verbal scores and MRT scores. This suggests that there might be some interference between spatial and verbal information processing. It is worth noting that a negative correlation between verbal and spatial factors was similarly found by 
Blazhenkova \& Kozhevnikov (2009). They also found negative correlations between OSIVQ object and spatial imagery measures which we did not find. Rather, our results indicate that object and spatial imagery are independent. The difference might be due to the number of items used in the two studies.

One limit of our study is that we were not able to evaluate the test-retest reliability and the ecological validity of this translated questionnaire. It could be interesting in the future to reevaluate some of our participants. Similarly, we could assess cognitive style in different professional domains or university courses as did Blazhenkova \& Kozhevnikov (2009). Our translated questionnaire still showed good psychometric properties. We believe that it was necessary to translate this questionnaire in order to provide a French tool that evaluates cognitive style while making the distinction between object and spatial imagery. Indeed, cognitive styles have important every-day life implications that need to be understood.

In fact, the original version of the OSIVQ has allowed many psychology and cognition researches that showed the importance of cognitive style. For instance, when learning with texts and pictures, learners' cognitive style might have a direct influence on learning behavior and preferences. Indeed, when learning with text-picture combinations, participants scoring high on the object scale and/or the spatial scale of the OSIVQ, relied more heavily on pictures than on texts while participants scoring high on the verbal scale tended to rely more on text (Höffler et al., 2017). Moreover, cognitive style seems also be linked with mathematical performances. "Spatial visualizers" had significantly higher spatial ability and performed better in mathematical tests than "object visualizers" (Haciomeroglu, 2016). Finally, cognitive style has been shown to influence spatial orientation. "Object visualizers" were better than "spatial visualizers" at recognizing visuals clues in an orientation task whereas "spatial visualizers" were better than "object visualizers" for judging relative positions between the visual clues (Kraemer et al., 2017). A link between cognitive style and creativity was also 
established. Object visualization seems to be linked to artistic creativity (physical creativity), spatial visualization is linked to scientific creativity (creativity in math and science), while both are distinct from verbal creativity (creativity in interpersonal relationships, communication, and writing) (Kozhevnikov et al., 2013).

In conclusion, our French translation of the OSIVQ presents good psychometric properties and is in agreement with the latest theories on cognitive style. Furthermore, this French version of the OSIVQ can certainly be a valuable tool for future psychological researches.

\section{Acknowledgments}

We thank Teresa Blicharska Strayer for her help in the translation of this questionnaire and Patrick Raynal for his insights on this article. We also thank undergraduate students for their assistance in data collection. We are grateful for participants' time and commitment.

\section{Funding}

This work was funded by the French National Research Agency (ANR-19-CE28-0012).

\section{References}

Albaret, J. M., \& Aubert, E. (1996). Etalonnage 15-19 ans du test de rotation mentale de Vandenberg, 8, 206-215.

Blajenkova, O., Kozhevnikov, M., \& Motes, M. A. (2006). Object-spatial imagery: A new self-report imagery questionnaire. Applied Cognitive Psychology, 20(2), 239-263. https://doi.org/10.1002/acp.1182 
Blazhenkova, O., \& Kozhevnikov, M. (2009). The new object-spatial-verbal cognitive style model: Theory and measurement. Applied Cognitive Psychology, 23(5), 638-663. https://doi.org/10.1002/acp.1473

Blazhenkova, O., \& Kozhevnikov, M. (2010). Visual-object ability: A new dimension of nonverbal intelligence. Cognition, 117(3), 276-301

Boswell, D. L., \& Pickett, J. A. (1991). A study of the internal consistency and factor structure of the Verbalizer-Visualizer Questionnaire. Journal of Mental Imagery

Chabris, C. F., Jerde, T. E., Woolley, A. W., Gerbasi, M. E., Schuldt, P., Bennett, S. L., Hackman, J. R., \& Kosslyn, S. M. (2006). Spatial and Object Visualization Cognitive Styles: Validation Studies in 3800 Individuals. 20.*

Deltour, J. J. (1993). Echelle de vocabulaire de Mill Hill de JC Raven. Adaptation française et normes européennes du Mill Hill et du Standard Progressive Matrices de Raven (PM38). Braine-le-Château: Editions l'application des techniques modernes.

Farah, M. J., Hammond, K. M., Levine, D. N., \& Calvanio, R. (1988). Visual and spatial mental imagery: Dissociable systems of representation. Cognitive Psychology, 20(4), 439-462. https://doi.org/10.1016/0010-0285(88)90012-6.

Guadagnoli, E., \& Velicer, W. F. (1988). Relation of sample size to the stability of component patterns. Psychological bulletin, 103(2), 265.

Haciomeroglu, E. S. (2016). Object-spatial Visualization and Verbal Cognitive Styles, and Their Relation to Cognitive Abilities and Mathematical Performance. Educational Sciences: Theory \& Practice, 16(3), 978-1003. https://doi.org/10.12738/estp.2016.3.0429

Hair, J. F., Black, W. C., Babin, B. J., Anderson, R. E., \& Tatham, R. L. (1998). Multivariate data analysis (Vol. 5, No. 3, pp. 207-219). Upper Saddle River, NJ: Prentice hall.

Höffler, T. N., Koć-Januchta, M., \& Leutner, D. (2017). More Evidence for Three Types of Cognitive Style: Validating the Object-Spatial Imagery and Verbal Questionnaire Using Eye Tracking when Learning with Texts and Pictures: Evidence for three types of cognitive style. Applied Cognitive Psychology, 31(1), 109-115. https://doi.org/10.1002/acp.3300 
IBM Corp. Released 2015. IBM SPSS Statistics for Windows, Version 23.0. Armonk, NY: IBM Corp.

Kosslyn, S. M., Thompson,W. L., \& Ganis, G. (2006). The case for mental imagery. New York, NY: Oxford University Press.

Kosslyn, S. M. (2005). Mental images and the Brain. Cognitive Neuropsychology, 22(3-4), 333-347. https://doi.org/10.1080/02643290442000130

Kosslyn, S. M., Ganis, G., \& Thompson, W. L. (2001). Neural foundations of imagery. Nature Reviews Neuroscience, 2(9), 635-642. https://doi.org/10.1038/35090055

Kozhevnikov, M., Kozhevnikov, M., Yu, C. J., \& Blazhenkova, O. (2013). Creativity, visualization abilities, and visual cognitive style. British Journal of Educational Psychology, 83(2), 196-209. https://doi.org/10.1111/bjep.12013

Kozhevnikov M, Blazhenkova O, Becker M. Trade-off in object versus spatial visualization abilities: Restriction in the development of visual-processing resources. Psychonomic Bulletin \& Review. 2010; 17(1):29-35. http://doi.org/10.3758/PBR.17.1.29. [PubMed: 20081157]

Kozhevnikov, M., Motes, M. A., \& Hegarty, M. (2007). Spatial visualization in physics problem solving. Cognitive science, 31(4), 549-579.

Kozhevnikov, M. (2007). Cognitive styles in the context of modern psychology: Toward an integrated framework of cognitive style. Psychological Bulletin, 133(3), 464-481. https://doi.org/10.1037/0033-2909.133.3.464

Kozhevnikov, M., Kosslyn, S., \& Shephard, J. (2005). Spatial versus object visualizers: A new characterization of visual cognitive style. Memory \& Cognition, 33(4), 710-726. https://doi.org/10.3758/BF03195337

Kozhevnikov, M., Hegarty, M., \& Mayer, R. E. (2002). Revising the Visualizer-Verbalizer Dimension: Evidence for Two Types of Visualizers. Cognition and Instruction, 20(1), 47-77. https://doi.org/10.1207/S1532690XCI2001_3

Kraemer, D. J. M., Schinazi, V. R., Cawkwell, P. B., Tekriwal, A., Epstein, R. A., \& Thompson-Schill, S. L. (2017). Verbalizing, visualizing, and navigating: The effect of strategies on encoding a large-scale virtual environment. Journal of Experimental Psychology: Learning, Memory, and Cognition, 43(4), 611-621. https://doi.org/10.1037/xlm0000314 
Lamm, C., Bauer, H., Vitouch, O., \& Gstättner, R. (1999). Differences in the ability to process a visuo-spatial task are reflected in event-related slow cortical potentials of human subjects. Neuroscience Letters, 269(3), 137-140

Linn, M. C., \& Petersen, A. C. (1985). Emergence and characterization of sex differences in spatial ability: A meta-analysis. Child Development, 56, 1479-1498.

Marks, D. F. (1973). Visual imagery differences in the recall of pictures. British Journal of Psychology, 64(1), 17-24.

Mayer, R. E., \& Massa, L. J. (2003). Three Facets of Visual and Verbal Learners: Cognitive Ability, Cognitive Style, and Learning Preference. Journal of Educational Psychology, 95(4), 833-846. https://doi.org/10.1037/0022-0663.95.4.833

Mazard, A., Tzourio-Mazoyer, N., Crivello, F., Mazoyer, B., \& Mellet, E. (2004). A PET meta-analysis of object and spatial mental imagery. European Journal of Cognitive Psychology, 16(5), 673-695. https://doi.org/10.1080/09541440340000484

McKelvie, S. J. (1994). Guidelines for judging psychometric properties of imagery questionnaires as research instruments: A quantitative proposal. Perceptual and Motor Skills, 79, 1219-1231.

Messick, S. (1976). Personality consistencies in cognition and creativity. Individuality in learning, 4, 22. Oxford, England: Jossey-Bass.

Motes, M. A., Malach, R., \& Kozhevnikov, M. (2008). Object-processing neural efficiency differentiates object from spatial visualizers. Neuroreport, 19(17), 1727-173

Nunnally JC. (1978) Psychometric theory. 2nd Edition. New York: McGraw-Hill.

Paivio, A. (1991). Dual coding theory: Retrospect and current status. Canadian Journal of Psychology Revue Canadienne de Psychologie, 45, 255-287.

Raven, J., Raven, J. C., \& Court, J. H. (2003). Manual for Raven's Progressive Matrices and Vocabulary Scales. San Antonio, TX: Harcourt Assessment.

Richardson, A. (1977). Verbalizer-visualizer: A cognitive style dimension. Journal of Mental Imagery, 1, 109-125.

Tabachnick, B.G. and Fidell, L.S. (2007). Using multivariate statistics (5 th ed). Boston: Allyn and Bacon. 
Tabachnick BG, Fidell LS. Principal components and factor analysis. Using multivariate statistics $2001 ; 4: 582-633$.

Vandenberg, S. G., \& Kuse, A. R. (1978). Mental rotations, a group test of three-dimensional spatial visualization. Perceptual and Motor Skills, 47(2), 599-604.

\section{Supplementary data}

\section{Questionnaire d'Imagerie Spatiale-Objet et Verbal (OSIVQ)}

Ceci est un questionnaire sur votre façon de penser. Merci de lire attentivement les affirmations suivantes et d'évaluer chacune d'elles sur une échelle de 5 points. Encerclez le «5» pour indiquer que vous êtes absolument d'accord avec l'énoncé. Encerclez le «1»pour indiquer que vous êtes totalement en désaccord avec cet énoncé. Entourez «3» si vous n'êtes pas sûr, mais essayez de faire un choix. Il est très important que vous répondiez à toutes les affirmations du questionnaire.

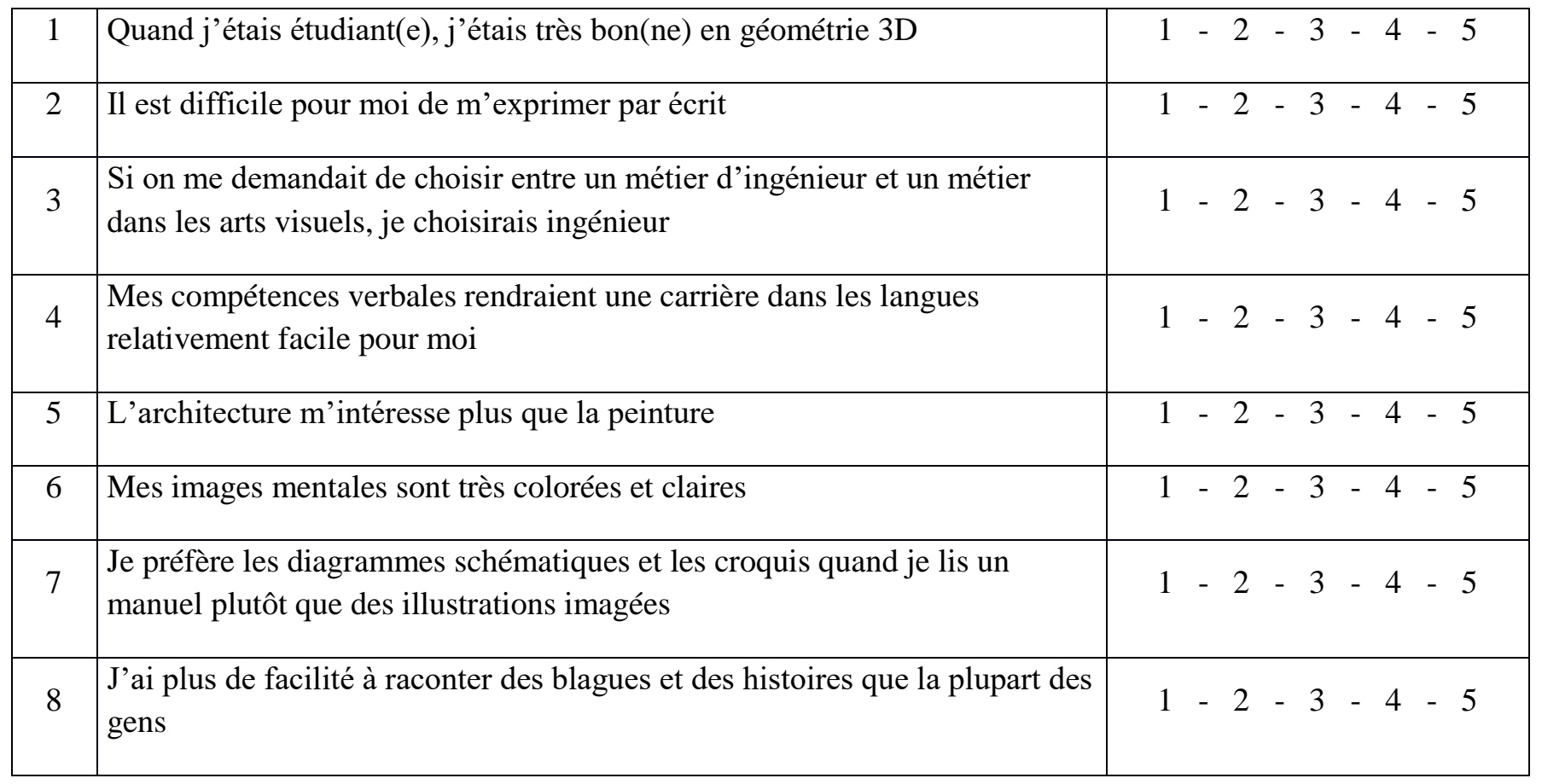




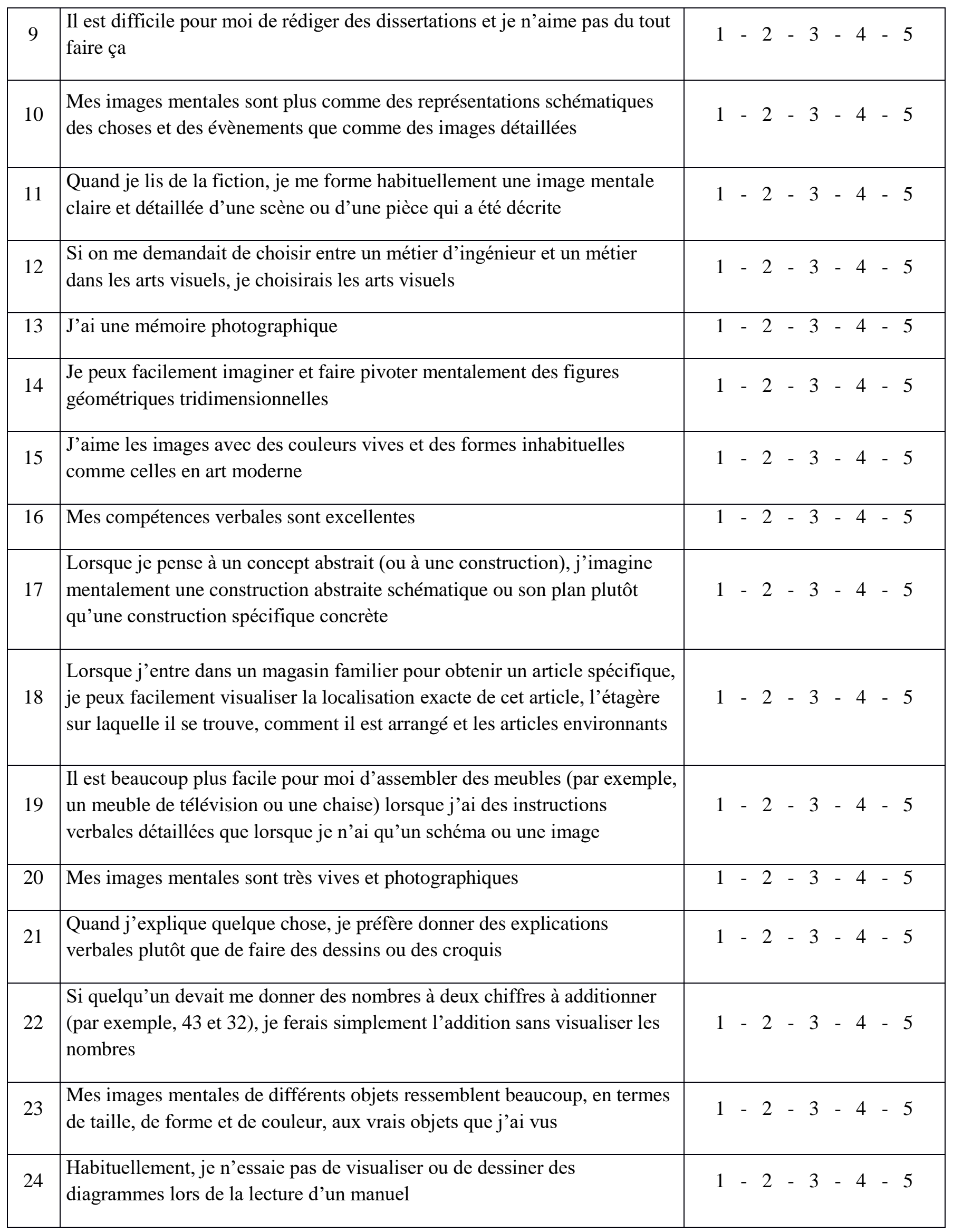




\begin{tabular}{|c|c|c|c|c|c|c|}
\hline 25 & $\begin{array}{l}\text { Normalement, je n'ai pas l'expérience de beaucoup d'images vives } \\
\text { spontanées. J'utilise mon imagerie mentale surtout lorsque j'essaie de } \\
\text { résoudre certains problèmes comme ceux en mathématiques }\end{array}$ & 1 & -2 & -3 & -4 & -5 \\
\hline 26 & $\begin{array}{l}\text { Quand j'imagine le visage d'un ami, j'ai une image parfaitement claire et } \\
\text { précise }\end{array}$ & 1 & -2 & -3 & -4 & -5 \\
\hline 27 & J'ai d'excellentes capacités en graphisme technique & 1 & -2 & -3 & -4 & -5 \\
\hline 28 & $\begin{array}{l}\text { Quand je me rappelle d'une scène, j'utilise des descriptions verbales plutôt } \\
\text { que des images mentales }\end{array}$ & 1 & -2 & -3 & -4 & -5 \\
\hline 29 & $\begin{array}{l}\text { Je peux facilement me rappeler d'un très grand nombre de détails visuels } \\
\text { que quelqu'un d'autre pourrait ne jamais remarquer. Par exemple, } \\
\text { j'enregistre automatiquement certaines choses comme de quelle couleur est } \\
\text { la chemise que quelqu'un porte ou de quelle couleur sont ses chaussures }\end{array}$ & 1 & -2 & -3 & -4 & -5 \\
\hline 30 & Je peux facilement dessiner un plan d'un bâtiment que je connais bien & 1 & -2 & -3 & -4 & -5 \\
\hline 31 & A l'école, je n'avais pas de problèmes avec la géométrie & 1 & -2 & -3 & -4 & 5 \\
\hline 32 & $\begin{array}{l}\text { Je suis bon(ne) pour jouer à des jeux spatiaux impliquant la construction à } \\
\text { partir de blocs et de papier (par exemple : Lego, Tetris, Origami) }\end{array}$ & 1 & -2 & -3 & -4 & -5 \\
\hline 33 & $\begin{array}{l}\text { Parfois, mes images mentales sont tellement vives et persistantes qu'il est } \\
\text { difficile de les ignorer }\end{array}$ & 1 & -2 & -3 & -4 & -5 \\
\hline 34 & $\begin{array}{l}\text { Je peux fermer les yeux et facilement percevoir une image d'une scène que } \\
\text { j'ai vécue }\end{array}$ & 1 & -2 & -3 & -4 & -5 \\
\hline 35 & Les mots me viennent plus facilement que la moyenne & 1 & -2 & -3 & -4 & -5 \\
\hline 36 & $\begin{array}{l}\text { Je préférerais avoir une description verbale d'un objet ou d'une personne } \\
\text { plutôt qu'une photo }\end{array}$ & 1 & -2 & -3 & -4 & -5 \\
\hline 37 & Je suis toujours conscient(e) de la structure des phrases & 1 & -2 & -3 & -4 & -5 \\
\hline 38 & Mes images sont plus schématiques que colorées et photographiques & 1 & -2 & -3 & -4 & 5 \\
\hline 39 & $\begin{array}{l}\text { J'apprécie d'être capable de reformuler mes pensées de nombreuses façons, } \\
\text { par souci de variation, à la fois à l'écrit et à l'oral }\end{array}$ & 1 & -2 & -3 & -4 & -5 \\
\hline 40 & $\begin{array}{l}\text { Je me rappelle de tout visuellement. Je peux décrire ce que les gens } \\
\text { portaient au diner et je peux parler de comment ils étaient assis et de quoi } \\
\text { ils avaient l'air, et ce, avec probablement plus de détails que je ne pourrais } \\
\text { discuter de ce qu'ils ont dit }\end{array}$ & 1 & 2 & -3 & -4 & 5 \\
\hline 41 & J'ai parfois un problème pour exprimer exactement ce que je veux dire & 1 & -2 & -3 & -4 & 5 \\
\hline 42 & $\begin{array}{l}\text { Je trouve cela difficile d'imaginer à quoi ressemblerait exactement une } \\
\text { figure géométrique tridimensionnelle lors d'une rotation }\end{array}$ & 1 & -2 & -3 & -4 & -5 \\
\hline
\end{tabular}




\begin{tabular}{|c|l|c|}
\hline 43 & Mes images visuelles sont dans ma tête tout le temps. Elles sont justes là & $1-2-3-4-5$ \\
\hline 44 & $\begin{array}{l}\text { Mes capacités graphiques rendraient une carrière dans l'architecture } \\
\text { relativement facile pour moi }\end{array}$ & $1-2-3-4-5$ \\
\hline 45 & $\begin{array}{l}\text { Quand j'entends un animateur radio ou un DJ que je n'ai jamais réellement } \\
\text { vu, je me retrouve généralement à imaginer à quoi il pourrait ressembler }\end{array}$ & $1-2-3-4-5$ \\
\hline
\end{tabular}

